\title{
Perceived representativeness, usefulness and impacts of using the nursing activities score as part of a workload readjustment initiative: A mixed methods study
}

\author{
Dominique Reda*1, Mélanie Lavoie-Tremblay ${ }^{2}$, Marie-Douce Primeau ${ }^{1}$ \\ ${ }^{1}$ École des sciences de la gestion, Université du Québec à Montréal, Canada \\ ${ }^{2}$ Mcgill University, Canada
}

Received: January 19, 2021

DOI: $10.5430 /$ jnep.v11n8p53
Accepted: April 7, 2021

Online Published: April 18, 2021

\begin{abstract}
Objective: Nursing workload has been shown to have negative impacts on job satisfaction, retention and turnover. The NAS is one of existing tools targeting nursing workload quantification. Although tested in multiple settings, few studies explored nurses' perception of its representativeness of workload, and its impacts when used to readjust nurse/patient ratios. This study was conducted to validate nurses' perception of representativeness and potential usefulness of the Nursing Activities Score (NAS) in regard to nurses' perceived workload and explore its impacts as part of a workload readjustment initiative.

Methods: A mixed method design was selected, combining semi-structured interviews ( $\mathrm{n}=13)$, and secondary analysis of project monitoring data for an entire intensive care unit $(n=139)$. Statistical analysis was performed using SPSS v.22 software for quantitative data, and qualitative data was analyzed through NVivo 12 software using a thematic deductive-mixed content analysis, aiming for the emergence of recurring themes.

Results: When taken as a whole, the NAS is perceived to be representative of nursing workload. However, validity concerns were identified at the tool completion level, notably in regard to improper documenting of events and fundamental understanding of the tool by nurses. Numerous impacts related to the use of the NAS were also identified.

Conclusions: Although the NAS appears to adequately represent nursing workload, its pertinent utility remains debatable due to high subjectivity described in this study. The sole use of the tool for patient assignment is therefore questionable.
\end{abstract}

Key Words: Nurses, Workload, Workload quantification tools, Nursing activities score

\section{BACKGROUND}

Most countries are facing acute nursing shortage. In the United States, for example, a study revealed that an approximate 260,000 additional nurses will be required by $2025^{[1]}$ and in Canada, that number turns around 60,000 by 2022. ${ }^{[2]}$ While many factors are associated to the nursing retention problem, workload appears to be one of the factors having most influence on nursing retention in regard to high turnover rates, workload distribution and staffing ratios, ${ }^{[3-5]}$ as well as on nurses' intent to stay or leave. ${ }^{[6,7]}$

Number of tools have been developed in order to objectively quantify nursing workload. The NAS, a tool developed in 2003 , is known to be one of the first tools allowing to quantify workload in terms of real number of hours of care rather than patient acuity. It is used to calculate the cumulative number of hours that a nurse spends caring for a patient on a

\footnotetext{
* Correspondence: Dominique Reda; Email: dominique.reda@hotmail.com; Address: École des sciences de la gestion, Université du Québec à Montréal, Canada.
} 
24-hour period, in order to help with staffing requirements. The tool, consisting of 23 items, was elaborated from another tool prior developed by Cullen and al. (1974), known as the Therapeutic Intervention Scoring System (TISS) and subsequently from its updated version, the TISS-28. ${ }^{[8]} \mathrm{Mi}-$ randa et al. (2003) adapted the tool in order to more precisely represent nursing workload in intensive care unit (ICU) by including all tasks performed as part of their profession role. ${ }^{[9]}$ According to studies, the NAS could potentially replace the TISS-28 altogether as $81 \%$ of nursing workload is identified by it, compared to $43 \%$ for the TISS- 28 .

Today, the NAS is used throughout ICU's mainly to assess appropriate patient-nurse ratios. Although some studies conducted focused on the NAS, none appear to focus on the validation of the tool through nurses' perceptions, nor adopt a qualitative approach. Consequently, the question here is to see whether using the NAS in ICU's is pertinent. The aim of this exploratory case study is to evaluate the pertinence of using the NAS as a workload quantification tool and has the following objectives: (1) to validate nurses' perceived representativeness of workload as portrayed by the NAS tool and (2) to explore its potential repercussions.

\section{MethodS}

\subsection{Study design}

A sequential mixed method design was selected for the course of this study, with a quantitative phase followed by a dominant qualitative component. Considering the complexity of the studied subject, a mixed method design allows to improve yielded results with secondary data sources, provide a more detailed explanation of quantitative results and explore qualitative data to further complement the quantitative component. ${ }^{[10]}$ Three important aspects influence the design of a mixed methods study according to Morse and Niehaus: the theoretical drive of a research question (qualitative or quantitative), the timing of components (concurrent or sequential), and the point of interface (moment where both components are integrated). ${ }^{[1]}$ A complementary data integration approach was selected in order to identify points of convergence or divergence of the yielded results using both quantitative and qualitative methods. More specifically, the qualitative approach in this study allowed for a deeper understanding of certain aspects identified through the quantitative approach, which would not have been as meaningful otherwise, as further specified in this manuscript.

\subsection{Quantitative component}

\subsubsection{Population and sampling}

For the quantitative component of the study, the sample comprised of an entire ICU team $(n=139)$ from a university health care center in Montreal, Canada. This sample includes bedside nurses and members of the nursing leadership team. All nurses were asked to complete a NAS chart during their working shift for a period of three months, for a total of 2649 NAS charts completed.

\subsubsection{Data collection}

Data was collected by means of a mobile application accessible both by mobile and desktop interface between August 6 and September 24, 2019. Nurses were mandated by the Nursing Leadership Team to fill out the NAS tool as well as to answer two additional questions which were added to the interface. These were filled out at the end of each work shift for each patient assigned. Data collected consists of sociodemographic data (age, gender, education level and years of employment), as well as project monitoring data, comprised of:

1) Detailed NAS chart and generated NAS score;

2) Work shift (night, day or evening shift);

3) Number of patients assigned per shift;

4) Nurse's perception of the NAS tool usefulness evaluated by the following question: "The NAS score is representative of my nursing workload": 1) Strongly agree 2) Agree 3) Neither agree nor disagree 4) Disagree 5) Strongly disagree (referred as NAS score representativeness in Tables 1 and 2).

\subsubsection{Data analysis}

Descriptive analysis and correlational analysis were performed for all variables of our model. A multivariate regression was then performed with NAS scores, sociodemographic variables and nurses' perception of the NAS' tool usefulness using SPSS v.22 software.

\subsection{Qualitative component \\ 2.3.1 Sampling}

For the qualitative component, participants were selected through non-probabilistic convenience sampling. Two brief presentations were held during team meetings on the unit in order to describe the aim and implications of the study. In total, 10 bedside nurses and 3 nurses from the leadership team were recruited. Saturation criteria guided the recruitment process. $^{[12]}$

\subsubsection{Data collection}

Data were collected through thirteen semi-structured individual interviews between October 3rd and October 31, 2019. The interview guide consists of five open-end questions pertaining to the tool's relevance $(\mathrm{n}=1)$, its perceived representativeness $(\mathrm{n}=1)$, as well as to the tool's potential impacts $(n=1)$, implementation experience $(n=1)$ and perceived usefulness $(n=1)$. 


\subsubsection{Data analysis}

Qualitative data were analyzed through content thematic analysis $^{[13]}$ using NVivo 12 software. Scientific rigor was optimized using Lincoln and Guba's (1985) four rigor criteria for trustworthiness. ${ }^{[14]}$ Credibility, or internal validity, was ensured through prompt transcription of interviews (maximal 48-hour delay) and through participant diversity. The latter was privileged in order to ensure, or rather optimise, an interpretation that is representative of the collected data.

As for transferability, or external validity, an in-depth description of the study's context as well as the methodology selected allowed for better judgment and reflection in regard to the obtained results' reproducibility, particularly in other contexts. It was important to see if the results yielded by this study could be reproduced in other ICU's, for example, or if they were only applicable for this particular research context and setting.

Dependability requires transparency from the researcher, as well as analyses that are independent of the researcher's fundamental beliefs or ideologies. ${ }^{[15]}$ Dependability was therefore met through data triangulation. Although the use of two distinct data sources and their triangulation may lead to some inconsistencies, one of its biggest advantage is that it can also highlight complementary aspects of the same observable phenomenon. ${ }^{[16]}$

Finally, individual coding by all members of the research team prior to data analysis ensured confirmability across this study. The numerous meetings and discussions with the research team ensured an informed consensus around the interpretation of obtained results, which also strengthened confirmability across this study.

\subsection{Ethical considerations}

Ethical approval was obtained by the hospital (5651, September 17, 2019) and university's (September 23, 2019) Committee Research Ethics' Board.

\section{ReSUltS}

\subsection{Quantitative data}

\subsubsection{Descriptive analysis}

Descriptive analysis was performed for both sociodemographic and project monitoring data. Refer to Table 1 for an overview of descriptive statistics.

Table 1. Frequency descriptive analysis

\begin{tabular}{|c|c|c|c|c|}
\hline Variable & $\begin{array}{l}\text { Sample }(n=2,649) \\
\%\end{array}$ & $\begin{array}{l}\text { Population }(n=139) \\
\%\end{array}$ & Variable & $\begin{array}{l}\text { Sample }(n=2,649) \\
\%\end{array}$ \\
\hline \multicolumn{3}{|l|}{ Sociodemographic } & \multicolumn{2}{|l|}{ Project monitoring } \\
\hline \multicolumn{3}{|l|}{ Age } & \multicolumn{2}{|l|}{ Shift } \\
\hline$<24$ & 5.0 & 5.0 & Day & 34.0 \\
\hline $25-34$ & 41.2 & 41.7 & Evening & 30.5 \\
\hline $33-44$ & 21.9 & 21.6 & Night & 35.4 \\
\hline $45-54$ & 23 & 20.9 & Number of patient & \\
\hline $55<$ & 8.9 & 10.8 & 1 & 59.1 \\
\hline \multicolumn{3}{|l|}{ Gender } & 2 & 40.9 \\
\hline Female & 82.7 & 81.3 & \multicolumn{2}{|c|}{ NAS score representativeness } \\
\hline Male & 17.3 & 18.7 & Strongly disagree & 1.1 \\
\hline \multicolumn{3}{|c|}{ Highest degree obtained } & Disagree & 6.2 \\
\hline College & 23.0 & - & Neutral & 22.5 \\
\hline Bachelors & 71.6 & - & Agree & 77.3 \\
\hline Graduate Degree & 5.4 & - & Strongly agree & 3.0 \\
\hline \multicolumn{5}{|c|}{ Work experience (years) } \\
\hline $1-2$ & 8.8 & 8.6 & & \\
\hline $3-4$ & 11.7 & 10.8 & & \\
\hline $5-9$ & 35.7 & 32.4 & & \\
\hline $10-14$ & 12.9 & 15.1 & & \\
\hline $15-19$ & 5.0 & 4.3 & & \\
\hline $20-24$ & 3.1 & 5.8 & & \\
\hline $25<$ & 12.3 & 12.9 & & \\
\hline
\end{tabular}




\section{1) Sociodemographic data}

Age

A large proportion of NAS forms (41.2\%) were completed by participants in the 25-34 age group, followed by a similar proportion for the 35-44 age group (21.9\%) and the 45-54 age group (23\%). As a minority, only $5 \%$ of forms were completed by participants aged under 24 and $8.9 \%$ by those aged 55 and over.

With regard to the sociodemographic data of the population in our study, they are well reflected by the forms completed using the NAS tool. In total, $5.0 \%$ of the population is in the under 24 age group, $41.7 \%$ in the $25-34$ age group, $21.6 \%$. in the $35-44$ age group, $20.9 \%$ in the $45-54$ age group and $10.8 \%$ in the 55 and over age group.

\section{Gender}

The majority of the 2,649 completed and considered valid forms were completed by female nurses $(82.7 \%)$, with male nurses representing only $17.3 \%$ of completed forms. In comparison, $81.3 \%$ of the study population is female and $18.7 \%$ is male.

\section{Highest degree obtained}

A tabulation of the frequency of completed forms in regard to the highest degree obtained was performed. The vast majority of forms $(71.6 \%)$ were completed by candidates whose highest degrees obtained correspond to bachelor's degrees (BAC), followed by Diploma of Collegial Studies' degrees (DEC) (23\%), and by Graduate degrees (Masters and Doctorates) (5.4\%).

\section{Work experience}

The largest proportion $(35.7 \%)$ of the 2,649 completed and considered valid forms were completed by nurses who have been working in the hospital's ICU between 5 and 9 years. In similar proportions are those filled by nurses who have less than one year experience (10.5\%), between 1 and 2 years $(8.8 \%)$, between 3 and 4 years $(11.7 \%)$, between 10 and 14 years $(12.9 \%)$ and over 25 years experience $(12.3 \%)$. A lower percentage of forms were completed by nurses with work experience between 15 and 19 years $(5.0 \%)$, as well as between 20 and 24 years.

With regard to the sociodemographic data of the population in our study, they are well reflected by the forms completed using the NAS tool. Work experience is evaluated at less than one year for $10.1 \%$ of the study population, between 1 and 2 years for $8.6 \%$ of the study population, between 3 and 4 years for $10.8 \%$ of the study population, between 5 and 9 years old for $32.4 \%$ of the study population, between 10 and 14 years old for $15.1 \%$ of the study population, between 15 and 19 years old for $4.3 \%$ of the study population, between
20 and 24 years old for $5.8 \%$ of the study population and over 24 years old for $12.9 \%$ of the study population.

\section{2) Project monitoring data}

\section{Shifts}

With regard to shifts, the results collected are rather proportional. Of the 2,649 forms completed during the collection period and considered valid, $34 \%$ of nurses completed them during the day shift, $30.5 \%$ during the evening shift and $35.4 \%$ during the night shift.

\section{Number of patients}

Nurses are assigned an average of one or two patients per shift, depending on the condition and acuity of the patient and staff availability. Of the 2,649 forms completed during the collection period, eight were rejected from the analysis because the information was missing. Therefore, of the 2,641 remaining records, nurses were assigned to one patient in $59.1 \%$ of instances, and to two patients in $40.9 \%$ of instances. During the data collection period, nurses were assigned on average to 1.41 patients.

\section{NAS scores}

The average NAS score obtained during the collection period is 737.54 . The lowest value obtained is 223 , and the highest is 1,617 . This therefore means that on average, $73.8 \%$ of the total time worked by the nurse is spent providing care to patients.

\section{NAS score representativeness}

The quantitative part of this study aimed to validate nurses' perceived representativeness of workload as portrayed by the NAS tool. Based on the descriptive data, study participants overall believe that the NAS score obtained during the shift is representative of their workload. In fact, in $70 \%$ of instances, nurses said they totally agreed $(3.0 \%)$ or agreed $(67.3 \%)$ with the fact that the score obtained was representative of their workload. In contrast, only $7 \%$ disagreed $(6.2 \%)$ or strongly disagreed $(1.1 \%)$ with the fact that the score obtained was representative of their workload. A little over a fifth of nurses $(22.5 \%)$ neither agreed nor disagreed that the score obtained was representative of the workload.

\subsubsection{Correlational analysis}

As shown in Table 2, it appears that the perception of representativeness of the NAS score is correlated significatively, but weakly, to four variables: age, gender, number of patients and NAS score. Using a simple Pearson's correlation coefficient, age and perception of representativeness of the NAS score is significative and negative $(\alpha=0.003)$, but very weak $(-.059 * *)$. Moreover, the correlation between gender and perception of representativeness of the NAS score is significative and positive $(\alpha=0.020)$, but very weak $\left(-.046^{*}\right)$. The 
correlation between the number of patients and the percep- negative $(\alpha=0.044)$, but very weak $\left(-.040^{*}\right)$. There does not tion of representativeness of the NAS score is significative seem to be a significative association between the perception and positive $(\alpha=0.001)$, but very weak $\left(-.064^{* *}\right)$. The cor- of representativeness of the NAS score and the two other relation between the obtained NAS score and the perception studied variables (work shift and highest degree obtained).

of representativeness of the NAS score is significative and

Table 2. Detailed bivariate correlations

\begin{tabular}{|c|c|c|c|c|c|c|c|c|c|}
\hline & & Age & Gender & Shift & $\begin{array}{l}\text { Number of } \\
\text { patients }\end{array}$ & $\begin{array}{l}\text { NAS } \\
\text { score }\end{array}$ & $\begin{array}{l}\text { NAS score } \\
\text { representa- } \\
\text { tiveness }\end{array}$ & $\begin{array}{l}\text { Highest } \\
\text { degree }\end{array}$ & $\begin{array}{l}\text { Work } \\
\text { experience }\end{array}$ \\
\hline \multirow{4}{*}{ Age } & Pearson & & & & & & & & \\
\hline & Correlation & & & & & & & & \\
\hline & Sig (bilateral) & & & & & & & & \\
\hline & $\mathrm{N}$ & & & & & & & & \\
\hline \multirow{3}{*}{ Gender } & $\begin{array}{l}\text { Pearson } \\
\text { Correlation }\end{array}$ & $.110^{* *}$ & & & & & & & \\
\hline & Sig (bilateral) & .000 & & & & & & & \\
\hline & $\mathrm{N}$ & 2649 & & & & & & & \\
\hline \multirow{3}{*}{ Shift } & $\begin{array}{l}\text { Pearson } \\
\text { Correlation }\end{array}$ & $.065^{* *}$ & $-.089 * *$ & & & & & & \\
\hline & Sig (bilateral) & .001 & .000 & & & & & & \\
\hline & $\mathrm{N}$ & 2649 & 2649 & 2649 & & & & & \\
\hline \multirow{3}{*}{$\begin{array}{l}\text { Number of } \\
\text { patients }\end{array}$} & $\begin{array}{l}\text { Pearson } \\
\text { Correlation }\end{array}$ & -.014 & .003 & .004 & & & & & \\
\hline & Sig (bilateral) & .482 & .892 & .847 & & & & & \\
\hline & $\mathrm{N}$ & 2641 & 2641 & 2641 & 2641 & & & & \\
\hline \multirow{3}{*}{ NAS score } & $\begin{array}{l}\text { Pearson } \\
\text { Correlation }\end{array}$ & -.002 & .005 & $-.130 * *$ & $-.336^{* *}$ & & & & \\
\hline & Sig (bilateral) & .902 & .781 & .000 & .000 & & & & \\
\hline & $\mathrm{N}$ & 2649 & 2649 & 2649 & 2641 & 2649 & & & \\
\hline \multirow{3}{*}{$\begin{array}{l}\text { NAS score } \\
\text { represen- } \\
\text { tativeness }\end{array}$} & $\begin{array}{l}\text { Pearson } \\
\text { Correlation }\end{array}$ & $-.059 * *$ & $-.046^{*}$ & -.018 & $.064 * *$ & $-.040^{*}$ & & & \\
\hline & Sig (bilateral) & .003 & .020 & .366 & .001 & .044 & & & \\
\hline & $\mathrm{N}$ & 2548 & 2548 & 2548 & 2542 & 2548 & 2548 & & \\
\hline \multirow{3}{*}{$\begin{array}{l}\text { Highest } \\
\text { degree }\end{array}$} & $\begin{array}{l}\text { Pearson } \\
\text { Correlation }\end{array}$ & $-.262 * *$ & $-.049 *$ & .015 & $.042 *$ & $.058^{* *}$ & .029 & & \\
\hline & Sig (bilateral) & .000 & .012 & .439 & .031 & .003 & .137 & & \\
\hline & $\mathrm{N}$ & 2649 & 2649 & 2649 & 2641 & 2649 & 2648 & 2649 & \\
\hline \multirow{3}{*}{$\begin{array}{l}\text { Work } \\
\text { experience }\end{array}$} & $\begin{array}{l}\text { Pearson } \\
\text { Correlation }\end{array}$ & $.779 * *$ & .016 & .026 & $-.048 *$ & $.046 *$ & $-.050 *$ & $-.141^{* *}$ & \\
\hline & Sig (bilateral) & .000 & .407 & .176 & .014 & .017 & .011 & .000 & \\
\hline & $\mathrm{N}$ & 2649 & 2649 & 2649 & 2641 & 2649 & 2648 & 2649 & \\
\hline
\end{tabular}

\subsubsection{Multivariate regression analysis}

The coefficient of determination (adjusted R-squared) indicates that our entire predilection model explains only $0.8 \%$ of the variance of the dependent variable. On another note, three out of the six independent variables have a significative effect at the $\alpha=0.05$ level. All other things being equal, being a woman corresponds to an increase of 0.075 of the perception of representativeness of the NAS score, each increase in patient number corresponds to an increase of 0.0077

Published by Sciedu Press of the perception of representativeness of the NAS score, and each increase of a year in nurses' age corresponds to a decrease of 0.004 of the perception of representativeness of the NAS score. No other variable obtained a significative effect at the $\alpha=0.05$ level.

According to these results, our predilection model does not appear to properly explain the observed phenomenon at the heart of the present study, which pertains to the representativeness of the NAS tool. This suggests that other factors can 
potentially explain the phenomenon more thoroughly, which are explored and identified in the qualitative component of this study.

\subsection{Qualitative data}

Out of the thirteen nurses who took part in this study's interviews, $38.5 \%$ were men and $61.5 \%$ were women, with a mean age of 44 years. More than half of them (53.9\%) had more than 10 years' work experience in ICU, and almost two thirds had more than 10 years' experience in the nursing field $(61.5 \%)$. As for education levels, half held a bachelor's degree $(53.9 \%)$.

In light of our analysis, three main themes were identified: NAS tool and composition, tool completion and repercussions of its utilisation.

When asked about the NAS' representativeness, most participants pointed out item categories, ponderation and intervention time intervals. The NAS tool's proposed categories were representative of workload, but the way these categories were divided and proposed time intervals were problematic.

A few participants mentioned categories being incomplete, or misrepresented. For example, many participants brought up the grouping of certain tasks under one category as being inaccurate. As one participant said, "the more they are grouped together, less the collected data is reliable."

Nurses also discussed the generalisation of results in regard to the tool's categories, expressing concern about obtained scores' validity, and consequently the use of a standardised item across different hospitals ICU settings, where patient type and frequency of tasks performed often differ. According to most participants, the categories should be tailored according to the ICU's specialisation as well as their typical clientele, as can be seen by one participant's comment in regard to the Becker drain: "I don't think it's appropriate for all ICUs because, I don't know how it works elsewhere for scores, but not all ICUs have cardiac surgeries (...) There are even categories that we never see, like the Becker drain.'

Out of the nine bedside nurses interviewed, eight mentioned the tool's proposed ponderation and time intervals as being problematic. Precisely, most comments were made in regard to the intervals' lack of precision. As pointed out by one participant: "Let's say you spent two hours, well you have the option of more than one hour or more than three. But if it's only two hours, you don't have that category to choose from. So for this reason, I think it was hard because either you lied or you say you did less."

The binary nature of certain pre-defined answer alternatives was also evoked by certain participants in this study. Many remarks were made about the administration of medication, which for some patients is required on numerous occasions rather than just one. As pointed out by a participant: "Let's say we have a patient; you only give him the meds once. And then that's it, it's finished. And then some patients you have to give it to them five, six times. But on the NAS, you can only choose yes or no."

When asked about the accuracy of the obtained NAS scores, participants had conflicting perceptions. Some said the score was mostly representative of their workload, while others said that it was not, for instance when they were caring for patients who did not fit "the norm". What came out unanimously were the circumstances under which the scores were not representative of the workload. Many participants stated that scores indicating a workload lower than anticipated were more frequent than ones indicating a workload higher than anticipated. Factors influencing the NAS score were identified by participants as being sociodemographics, patient acuity, patient variability and work shift.

In regard to demographics, most participants identified the nurses' individual profile as impacting generated scores, stating that younger and novice nurses might require more time to complete certain tasks than senior nurses, therefore impacting NAS scores.

Many participants mentioned patient acuity as a factor influencing the NAS tool completion, although no consensus was expressed. Some said that scores for acute patients were often not representative of their workload in comparison to chronic patients since the latter's condition is less likely to change in comparison to that of an acute patient. Others said that chronic patients' scores were no more representative than that of acute patients.

The fact that a patient's condition varies in time can also influence the NAS score, demonstrating that NAS scores are only points in time and consequently represent a challenge for patient assignment since variations are incontrollable and unforeseeable. A given example is that of a NAS score being higher for a patient immediately post-operation.

Moreover, as some tasks are more commonly executed during certain shifts, the NAS score is seen to fluctuate accordingly. NAS scores were found to fluctuate depending on whether they are tabulated during a day, evening or night shift, since some tasks are done more frequently during day shifts (for example, dressings) than during evening or night shifts.

Completion concerns were pointed out by participants, especially pertaining to inadequate documentation, use of technology and understanding of the tool and its items. NAS 
completion might be faulty due to lack of time. Often are times where nurses had to complete the NAS and would forget what tasks were previously completed as they were pressed by time. As pointed out by a participant, the timing of the required NAS tool completion is not always optimal, especially for instances where nurses are facing high workloads. Another point brought up is setting task priorities. Many participants admitted that the NAS was sometimes set aside due, once again, to lack of time, as focusing on the patient is a nurses' priority.

Surprisingly, some participants evoked the sentiment of fear which took over the unit during the tool's implementation process. Some nurses admitted to altering and manipulating some items' score in order to better reflect their perceived workload. The reasons given for that behavior are identified as the recently frequent budget and staffing cuts, burnouts, injuries and high turnover. As pointed out by a participant, "Initially, nurses either didn't fill it out or were trying to justify making their NAS artificially high in order to justify being singled on a patient that didn't really need to be singled. Because they are worried that you guys will find that we are overstaffed, which I don't think will ever be the case".

The use of technology for tool completion was identified both positively and negatively by participants. In the latter case, it was found that older nurses seem to have more reservations about having to complete another administrative task using mobile interfaces. One nurse mentioned that to her knowledge, many nurses still didn't know how to use the application and therefore were not completing the NAS scores.

Given that the tool had only been implemented on the unit for a short period of time (only about six months) at the time of interviews, not many changes were observed by nurses other than the fact that the tool allowed for visualisation of workload, and that its implementation impacted the work environment. Nevertheless, participants did identify potential and foreseen uses related to using the tool, mostly concerning its use for patient assignment as well as the hope to see greater staffing.

Some nurses found that filling out the NAS was useful to assess, visualise and be aware of their personal workload.

Others mentioned that completing the NAS is perceived as an addition to their workload, but that it is still manageable as it is not a lengthy task to complete.

Some expectations and apprehensions were also pointed out by nurses. According to certain participants, adopting NAS use on the unit represents a certain threat, as the projected real use of the tool does not appear to have been disclosed to

Published by Sciedu Press nurses. Some nurses mentioned fearing NAS results indicating a nursing surplus that would result in staffing cuts. As pointed out by a participant, "There is that danger of it not being representative enough, and that we would then be in... deep dooodoo (laughs). Saying: well 30 beds, you're only supposed to be 15 nurses, ahhh".

Participants were unanimous in stating that the sole use of the NAS for patient assignment would not be adequate, as the NAS score only represents a glimpse of the situation. Variability of the patient's condition and therefore of foreseen procedures are reasons why the NAS should not solely be used for patient assignments. At the present time, patient assignment on the unit is done by nurses in charge who walk around the unit to gather information to aid them for decision making. The NAS therefore constitutes an important aid for patient assignment when challenged with lack of time, in order to decide whether a patient will be doubled or not.

\section{Discussion}

This study is relevant as it exposes the reality of using quantification tools, as perceived by nurses themselves. According to prior findings, this had not yet been studied. One of our objectives was to validate perception of representativeness of the NAS tool from nurses' perspective. Even though obtained NAS scores were found to be fairly representative of workload based on the results gathered from the quantitative component, the qualitative component of this research identified reasons as to why that was or was not the case. This further insight allowed for clarification and deeper understanding of the phenomenon, which would not have risen if a mixed method study was not privileged. Specific situations in which the NAS scores were or were not representative of workload were therefore identified.

The tool and its composition have been questioned by many participants. Although the tool seems to include all nursing tasks, many stated that nursing workload cannot be summarized into tool format simply due to the core nature of the nursing profession, which is comprised of aspects that are not explicitly apparent, supporting existing studies. ${ }^{[17]}$ Consequently, calculated workload may be inaccurate and result in work overload associated to lack of time and inadequate resource distribution. ${ }^{[18]}$

It is reasonable to conclude that the NAS tool is representative of nursing workload, as participants identified the tool as representing workload at $70 \%-80 \%$ levels, which corresponds to other studies' findings. ${ }^{[9]}$ The qualitative component of this study allowed for better understanding of the factors that have an influence on the NAS score as well as its representativeness, which the quantitative component was 
not able to achieve. The most mentioned factor is the high level of subjectivity associated to the tool use. Other factors range from experience and age to circumstances under which the tool is used and completed. According to participants, the obtained scores do not always appear to be representative of workload. One possible explanation for that is that tool comprehension and mastering is a great challenge for units where turnover rates are high.

Given the results obtained through this study, it is reasonable to consider using NAS results to quantify workload and assign patients. However, it is important for management to exercise judgment. As previously mentioned, participants identified many situations where the use of NAS scores for patient assignment would have resulted in improper assignment and staffing ratios, given NAS scores are not always representative of their perceived workload. It is important to maintain adequate staffing ratios as they are associated to greater work satisfaction, less burnout as well as better quality of care. ${ }^{[19]}$

As for repercussions, what surprisingly stemmed from this study is the high number of participants expressing fear in regard to the real purpose of the NAS integration on their unit. As stated by Twigg and McCullough (2014), work environment has an impact on intent to stay or leave of nurses, as well organisational climate. ${ }^{[20]}$ A lack of communication and clarification on the real intent of use of the NAS tool on the unit can negatively impact organisational climate and work environment, as this study allowed to show. Many participants admitted fearing eventual staffing cuts, and mentioned experiencing resistance to change within the unit, especially where older nurses are concerned. As for potential usefulness, the NAS has been found to be useful for patient assignment, but only as a complement to current methods and should not ultimately be used in replacement of. The reason for this is that patient assignment in itself is a subjective task exposed to constant changes related to a patients' condition and implication. Tasks to be performed are not reflected in the NAS tool and are an important aspect of patient assignment, and therefore should not be neglected. These results partially contradict that of certain quantitative studies; studies conducted by Ducci and Padilha (2008) as well as Marques and al. (2013) found no difference in comparing NAS scores associated to prospective and retrospective tool completion, therefore stating that the NAS tool could be used both ways. ${ }^{[21,22]}$

\subsection{Limitations}

This study was done in one unit only. Therefore, it would be interesting to conduct a future study with a more various population consisting of nurses from across different hospitals, provinces as well as countries.

\subsection{Implications for nursing management}

As nursing workload has been associated in the literature with important factors pertaining to the nursing shortage, such as satisfaction, retention and turnover, more and more policymakers and nursing leadership members are expressing interest toward workload quantification tools. Although the NAS as a tool appears to be representative and valid, its sole use for patient assignment is questionable because of validity concerns. We therefore recommend policymakers and nursing management to use the NAS as a complement to the current assignment method rather than in replacement of. Moreover, its standardized use is also questionable due to validity concerns associated to tool completion. Given this study's findings, policymakers and nursing management should evaluate and assess the benefits versus costs of using the NAS on their unit, depending on their needs. We believe that the tool should be tailored for the targeted environment before being fully integrated, and that nurses must fully comprehend it.

\section{Conclusion}

This study included a qualitative component to target nurses' perspectives. It may be concluded that the NAS tool and its composition are representative of nursing workload, but that on another note, validity concerns exist in regard to tool use and completion by ICU nurses.

\section{CONFlicts OF INTEREST Disclosure}

No conflict of interest has been identified by the authors.

\section{REFERENCES}

[1] Buerhaus PI, Donelan K, Ulrich BT, et al. Impact of the Nurse Shortage on Hospital Patient Care: Comparative Perspectives. Health Affairs. 2007; 26: 853-862. PMid:17485766 https://doi.org/ $10.1377 /$ hlthaff .26 .3 .853

[2] Canadian Nurses Association. Tested solutions for eliminat ing Canada's Registered Nurse Shortage. 2009. Available from: https://cna-aiic.ca/ /media/cna/page-content/p df-en/rn_highlights_e.pdf

[3] Buchan J, Shaffer FA, Catton H. Policy Brief: Nurse Retention. International Centre on Nurse Migration. 2018. Available from: https://www.icn.ch/sites/default/files/inl ine-files/2018_ICNM\%20Nurse\%20retention.pdf

[4] Chen YC, Guo YLL, Chin WS, et al. Patient-Nurse Ratio is Related 
to Nurse's Intention to Leave Their Job through Mediating Factors of Burnout and Job Dissatisfaction. International Journal of Environmental Research and Public Health. 2019; 16: 1-14. PMid:31795420 https://doi.org/10.3390/ijerph16234801

[5] Shin S, Park J, et Bae S. Nurse staffing and nurse outcomes: A systematic review and meta-analysis. Nursing Outlook. 2018; 66: 273-282. PMid:29685321 https://doi.org/10.1016/j . outlook. 2017 .12 .002

[6] Lavoie-Tremblay M, Paquet M, Duschesne MA, et al. Retaining Nurses and Other Hospital Workers: An Intergenerational Perspective of the Work Climate. Journal of Nursing Scholarship. 2010; 42: 414-422. PMid:21091624 https://doi.org/10.1111/j.15 $47-5069.2010 .01370 . x$

[7] Stone PW, Mooney-Kane C, Larson EL, et al. Nurse Working Conditions, Organizational Climate, and Intent to Leave in ICUs: An Instrumental Variable Approach. Health Services Research. 2007; 42: 1085-1104. PMid:17489905 https://doi.org/10.1111/j. 1475-6773.2006.00651.x

[8] Cullen DJ, Civetta JM, Briggs BA, et al. Therapeutic Intervention Scoring System: a method for quantitative comparison of patient care. Crit Care Med. 1974; 2: 57-60. PMid:4832281 https: //doi.org/10.1097/00003246-197403000-00001

[9] Miranda DR, Nap R, de Rijk A, et al. Nursing activities score. Crit Care Med. 2003; 31: 374-382. PMid:12576939 https://doi .or g/10.1097/01.CCM.0000045567.78801.CC

[10] Creswell JW, et Plano Clark VL. Designing and conducting mixed research. Thousand Oaks, CA: Sage Publications; 2007.

[11] Buchholtz N. Planning and Conducting Mixed Methods Studies in Mathematics Educational Research.Compendium for Early Career Researchers in Mathematics Education, ICME-13 Monographs. 2019; 131-152. https://doi.org/10.1007/978-3-030-15636-7_6

[12] Saunders B, Sim J, Kingstone T, et al. Saturation in qualitative research: exploring its conceptualization and operationalization. Quality \& Quantity. 2017; 52: 1893-1907. PMid:29937585 https : //doi.org/10.1007/s11135-017-0574-8
[13] Miles M, Huberman M, et Saldana J. Qualitative Data Analysis: A Methods Sourcebook. 3rd ed. Thousand Oaks, CA: SAGE; 2014.

[14] Lincoln YS, et Guba EG. Naturalistic inquiry. Berverly Hills, California: Sage Publications; 1985.

[15] Gohier C. De la démarcation entre critères d'ordre scientifique et d'ordre d'éthique en recherche interprétative. Recherches qualitatives. 2004; 24: 3-17. http://www.recherche-qualitative.qc.ca/documents/f iles/revue/edition_reguliere/numero24/24gohier.pdf

[16] Patton MQ. Qualitative Research \& Evaluation Methods (3e éd.). Thousand Oaks: Sage Publications; 2002.

[17] Morris R, MacNeela P, Treacy P, et al. Reconsidering the conceptualization of nursing workload: literature review. Journal of Advanced Nursing. 2007; 57: 463-471. PMid:17284279 https: //doi.org/10.1111/j.1365-2648.2006.04134.x

[18] Ross C, Rogers C, et King C. Safety culture and an invisible nursing workload. Collegian. 2019; 26: 1-7. https://doi.org/10.1016/ j.colegn.2018.02.002

[19] Aiken LH, Sloane DM, Cimmiotti JP, et al. Implications of the California Nurse Staffing Mandate for Other States. Health Services Research. 2010; 45: 904-921. PMid:20403061 https://doi.org/ $10.1111 / \mathrm{j} .1475-6773.2010 .01114 . x$

[20] Twigg D, et McCullough K. Nurse retention: A review of strategies to create and enhance positive practice environments in clinical settings. International Journal of Nursing Studies. 2014; 51: 85-92. PMid:23809644 https://doi.org/10.1016/j.ijnurstu. 201 3.05 .015

[21] Ducci AJ, et Padilha KG. Nursing activities score : estudo comparativo da aplicação retrospective e prospective em unidade de terapia intensiva. Acta Paulista de Enfermagem. 2008; 21: 581-587. https://doi.org/10.1590/S0103-21002008000400008

[22] Marques RS, Zeitoun SS, de Lara MR, et al. Dimensionamento de pessoal relacionado à assistência ao paciente crítico com o uso do Nursing Activities Score nas formas prospective e retrospective. J Health Sci Ints. 2013; 31: 149-154. 